\title{
A New Method for Horizontal Axis Wind Turbine (HAWT) Blade Optimization
}

\author{
Mohammadreza Mohammadia, Alireza Mohammadib and Said Farahatc \\ ${ }^{a}$ Bushehr Gas Company, Iranian National Gas company, Iran \\ ${ }^{b}$ Gotvand irrigation \& Drainage operational Network Company \\ c Sistan and Baluchestan University, Department of Mechanical Engineering, Iran
}

\begin{abstract}
Iran has a great potential for wind energy. This paper introduces optimization of 7 wind turbine blades for small and medium scales in a determined wind condition of Zabol site, Iran, where the average wind speed is considered $7 \mathrm{~m} / \mathrm{s}$. Considered wind turbines are 3 bladed and radius of 7 case study turbine blades are $4.5 \mathrm{~m}, 6.5 \mathrm{~m}, 8 \mathrm{~m}, 9 \mathrm{~m}, 10 \mathrm{~m}, 15.5 \mathrm{~m}$ and $20 \mathrm{~m}$. As the first step, an initial design is performed using one airfoil (NACA 63-215) across the blade. In the next step, every blade is divided into three sections, while the $20 \%$ of first part of the blade is considered as root, the $5 \%$ of last the part is considered as tip and the rest of the blade as mid part. Providing necessary input data, suitable airfoils for wind turbines including 43 airfoils are extracted and their experimental data are entered in optimization process. Three variables in this optimization problem would be airfoil type, attack angle and chord, where the objective function is maximum output torque. A MATLAB code was written for design and optimization of the blade, which was validated with a previous experimental work. In addition, a comparison was made to show the effect of optimization with two variables (airfoil type and attack angle) versus optimization with three variables (airfoil type, attack angle and chord) on output torque increase. Results of this research shows a dramatic increase in comparison to initial designed blade with one airfoil where two variable optimization causes $7.7 \%$ to $22.27 \%$ enhancement and three variable optimization causes $17.91 \%$ up to $24.48 \%$ rise in output torque .
\end{abstract}

Keywords: Optimization, Wind turbine blade, Airfoil, Aerodynamics, Wind Turbine Output Torque

Article History: Received Oct 15, 2015; Received in revised form January 2, 2016; Accepted January 14, 2016; Available online

How to Cite This Article: Mohammadi, M., Mohammadi, A. and Farahat, S. (2016) A New Method for Horizontal Axis Wind Turbine (HAWT) Blade Optimization. Int. Journal of Renewable Energy Development, 5(1),1-8.

http://dx.doi.org/10.14710/ijred.5.1.1-8

\section{Introduction}

Regarding increasing demand of energy in developing countries like Iran, it is completely essential to develop renewable energies despite huge amount of fossil fuel resources. Besides this reason, fossil fuel usage deduced huge effects on climate and environment, which makes it necessary to work on renewables like wind (Nedaei 2015). Wind turbine industry has a very good progress worldwide that nominates wind as a more reliable and less expensive energy resource in near future (Mohammadi et al. 2015).

Wind energy has a growing market and some recent researches have been considering potential of different countries to develop this industry such as Qafleshi et al. (2015) who worked on potential of wind energy in
Albania and Kosovo, and Allali et al. (2015) was working on technological and economic aspects of Wind-Diesel power systems in South Algeria. As wind turbine blade has a significant effect on turbine output power and efficiency, several researches have been performed about wind turbine blade optimization.

Cencelli (2006) worked on airfoil design for increasing the output power. In this research, four sections were considered and for each section, new airfoils were designed. Polat and Tuncer (2013) kept wind speed, rotor speed and rotor diameter as constants and aerodynamic shape optimization method was applied with XFOIL. In Sharifi and Nobari's work (2013), pitch angle optimization was the purpose of research using an aerodynamic code to predict the performance of horizontal axis wind turbines. Although studies of Chen et al. (2013) was about structure of

${ }^{*}$ Corresponding Author:

Email: mhrz_mohammadi@yahoo.com.au 
Citation: Mohammadi, M., Mohammadi, A. and Farahat, S. (2016) A New Method for Horizontal Axis Wind Turbine (HAWT) Blade Optimization. Int. Journal of Renewable Energy Development, 5(1), 1-8. http://dx.doi.org/10.14710/ijred.5.1.1-8

$\mathrm{P}$ a g e $\mid 2$

blade and the purpose of research was reducing weight of blade, which may not be relevant to this paper, they used airfoil families for one blade, which means using more than one airfoil in a blade. Mahmoodi et al. (2014) used BEM theory for wind turbine rotor simulation where CFD was used as the numerical solution procedure. Sedaghat et al. (2014) pursued the purpose of increasing power using a BEM (blade element momentum) analysis, while wind speed was considered variable. Zhu et al. (2014) proposed new airfoil families for a given rotor diameter and a tip speed ratio, working on increasing power coefficient in large wind turbines. Pourrajabian et al. (2014) worked on the influence of the air density variation with altitude on the performance of a small-scale horizontal axis wind turbine blade. Ying et al. (2015) studied on the airflow properties of a novel small-scale wind turbine. Results of this research showed an increase in the maximum flow velocity and power coefficient.

In all mentioned researches horizontal axis wind turbine blade (HAWT) is considered because this type of wind turbine is used commercially worldwide and other types of wind turbine such as vertical axis wind turbines or high altitude wind turbines are not very common yet (Mohammadi et al. 2014). Similar to most mentioned researches, the purpose of this paper is maximizing output torque and power based on certain parameters. Due to assumption of constant angular velocity maximizing the output torque will lead to maximum output power too. The other similarity of this research is using BEM theory as the blade design tool, which is completely common in all wind turbine blades researches. In contrast, this research focuses on three important parameters, airfoil type, attack angle and chord distribution which have been neglected in previous researches. This research does not provide any airfoil design such as Cencelli (2006) and Zhu et al. (2014) but it will investigate the effect of current airfoil usages in a blade when several airfoils are used in different parts of the blade. This research provides both design and optimization for horizontal axis wind turbine. Optimization method is completely inventory and can be used for any other condition worldwide, but this optimization should be compared with a primary design for a local condition to show the effect of optimization method in the selected condition.

Wind turbines can be classified according to their size. Small scale turbines are less than $25 \mathrm{KW}$, while intermediate (medium) scale wind turbines have a capacity between 25 and $150 \mathrm{KW}$ and large wind turbines have a capacity range between $150 \mathrm{KW}$ to 5 MW (Kurniadi 2002). According to this classification, blades considered in this paper are classified as small and medium scale wind turbine blades. These blades are $4.5 \mathrm{~m}, 6.5 \mathrm{~m}, 8 \mathrm{~m}, 9 \mathrm{~m}, 10 \mathrm{~m}, 15.5 \mathrm{~m}$ and $20 \mathrm{~m}$ blades, designed for $5 \mathrm{KW}, 10 \mathrm{KW}, 15 \mathrm{KW}, 20 \mathrm{KW}, 25$ $\mathrm{KW}, 60 \mathrm{KW}$ and $100 \mathrm{KW}$ output power respectively for Zabol site where average wind speed is $7 \mathrm{~m} / \mathrm{s}$.

\section{Zabol Wind Energy Site condition}

Iran has a developing economy and needs huge amount of electricity. Studies and calculations have shown that wind energy potential capacity in 26 regions (including over 45 sites), considering 33\% efficiency, is about 6500 MW (Suna website 2015).

Iran presents a unique wind energy situation, while the range of wind speed in Iran compared to the international market is low (Gandomkar 2008). This indicates the need of specific technology related to the low wind speed conditions of Iran. Figure 1 shows Iran wind speed atlas in 80 meters height.

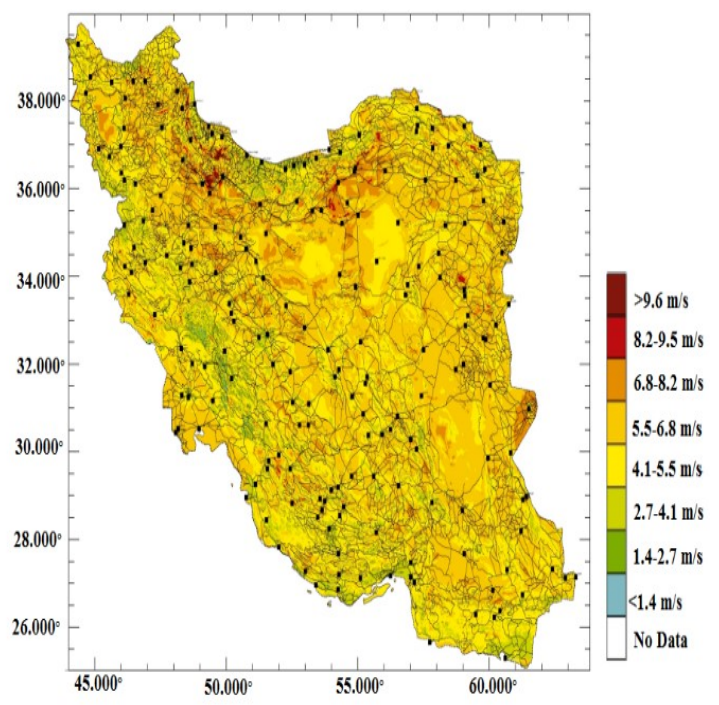

Figure 1 Wind speed atlas in Iran in 80 meters height

\section{Blade Design Theories}

Some theories have been developed for horizontal axis wind turbine blade design and performance prediction known as Blade Element theory, Momentum theory and Blade Element Momentum (BEM) theory. Blade Element Momentum theory combines Momentum theory and Blade Element theory to calculate the blade shape and to predict the performance parameters of the rotor for ideal and steady operating conditions. This theory is the most popular analysis of wind turbine blade, as it is a fast way to solve analysis problems and gives accurate results in steady state conditions (Kulunk 2011). In this theory, the blade is divided into n sections and $r$ is defined as distance of a section from rotation axis. Figure 2 shows sectioning method in BEM theory and illustrates how $r, R$ and $c$ is defined. In this figure, $r$ is sectional blade radius, $\mathrm{R}$ is blade radius and $\mathrm{c}$ is chord length. 


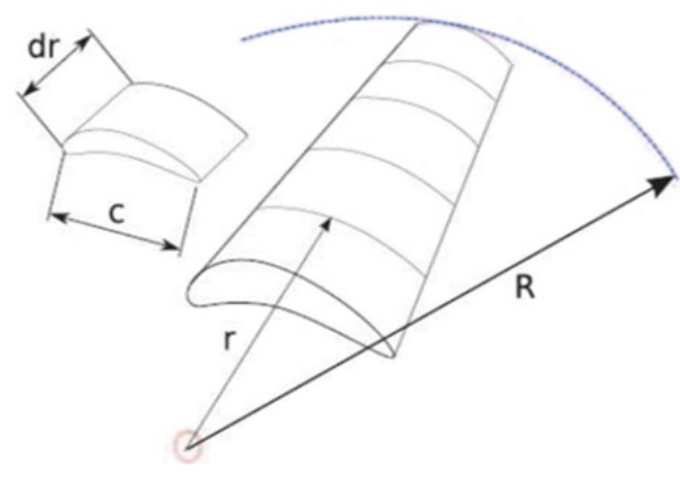

Figure 2 shows sectioning method in BEM theory (Kulunk 2011)

In Blade Element Momentum theory $\lambda_{r}$ is defined as local tip speed ratio and calculated as equation 1 (Manwell and McGowan 2009):

$$
\lambda_{r}=\frac{r \Omega}{U}
$$

Where $r$ is local blade radius, $\Omega$ is blade angular velocity and $U$ is stream velocity. Tip velocity ratio $(\lambda)$ is defined as tip velocity to stream velocity ratio (see Equation 2).

$$
\left(\lambda_{r}\right)_{i}=\lambda_{R}^{r_{i}}
$$

Tip velocity ratio is selected based on turbine performance condition. The best performance can be obtained with the assumption of $\lambda=10$ and three bladed turbine. In Equation 2, $r_{i}$ is the radius of every blade section and $\mathrm{R}$ is radius of the blade. According to equation 3 , relative wind angle with rotation plane can be obtained.

$\phi_{\mathrm{i}}=\frac{2}{3} \tan ^{-1}\left(\frac{1}{\left(\lambda_{r}\right)_{i}}\right)$

Chord distribution in each section of the blade can be obtained from equation $4[13,14]$ :

$$
C_{\mathrm{i}}=\frac{8 \pi \mathrm{r}_{\mathrm{i}}}{B \mathrm{C}_{\mathrm{L}}}\left(1-\cos \left(\emptyset_{l}\right)\right)
$$

Where $C_{L}$ is lift coefficient and B is number of turbine blades which is assumed to be three bladed in this research.

In these equations $i$ is number of each blade section. According to Equation, 3 and 4 primary values of relative wind angle and chord for every section of the blade will be provided. However according to Blade Element Momentum theory not only these two parameters but also other effective parameters such as attack angle must be modified based on tip loss effect.
Tip loss factor can be calculated from equation 5 (Manwell and McGowan 2009).

$$
F=\frac{2}{\pi} \cos ^{-1}\left(\exp \left(-\frac{\frac{B}{2}\left(1-\frac{r}{R}\right)}{\frac{r}{R} \sin (\phi)}\right)\right)
$$

According to BEM theory lots of equations are used for design calculations of a wind turbine blade which can finally deduce to calculations of forces applied on the blade. In this theory $d F_{N}$ is a component of total force applied on the rotor and is located parallel to axial force [see equation 6]. $d F_{T}$ is perpendicular to the direction of and is located in the plane of blade rotation [see equation 7] (Manwell and McGowan, 2009).

$\mathrm{d} F_{N}=B \frac{1}{2} \rho U_{r e l}^{2}\left(C_{L} \cos (\phi)+C_{d} \sin (\phi)\right) c d r$

$\mathrm{d} F_{T}=B \frac{1}{2} \rho U_{r e l}^{2}\left(C_{L} \sin (\phi)-C_{d} \cos (\phi)\right) c d r$

Where B is number of blades, $\rho$ is air density, $U_{\text {rel }}$ is relative wind velocity, $C_{L}$ is lift coefficient, $C_{d}$ is drag coefficient, $\phi$ is angle of relative wind, $c$ is chord length and $\mathrm{r}$ is local radius. The torque due to $d F_{T}$ which is applied in distance of $r$, is calculated by equation 8 .

$d Q=B \frac{1}{2} \rho U_{r e l}^{2}\left(C_{L} \sin (\emptyset)-C_{d} \cos (\emptyset)\right) c r d r$

Reynolds number across the blade can be calculated by equation 9 (Manwell and McGowan 2009).

$$
R e=U_{\text {rel }} * c / \vartheta
$$

In this equation $\mathrm{Re}$ is Reynolds number as a dimensionless number; $U_{r e l}$ is relative wind velocity of the desired blade element based on m/s; c is chord length based on meter and finally $\vartheta$ is kinematic viscosity based on $\mathrm{m}^{2} / \mathrm{s}$.

\section{Materials and Methods}

Wind turbine optimization was performed by a MATLAB code, which uses Blade Element Momentum analysis for calculating output torque of every selected section.

Different parameters were used in Blade Element Momentum analysis which can be entered in optimization process; these parameters include turbine diameter, number of blades, chord length, attack angle, airfoil type etc (Mohammadi 2015).

In this research, airfoil type, attack angle and chord are optimization variables, while relative wind angle distribution, wind speed, blade length and number of 
Citation: Mohammadi, M., Mohammadi, A. and Farahat, S. (2016) A New Method for Horizontal Axis Wind Turbine (HAWT) Blade Optimization. Int. Journal of Renewable Energy Development, 5(1), 1-8. http://dx.doi.org/10.14710/ijred.5.1.1-8

$\mathrm{P}$ a g e $\mid 4$

blades considered as constants. Table 1 shows optimization problem briefly.

Table 1.

Optimization problem difinition

\begin{tabular}{cc}
\hline \multicolumn{2}{c}{ Optimization parameters } \\
\hline Objctive Function & Output torque \\
Variables & Attack Angle , Airfoil type and chord \\
Attack angle range & $0-12$ degrees \\
Constants & Turbine Diameter,Wind speed, \\
& Number of blades, relative wind angle \\
\hline
\end{tabular}

Airfoils are selected from Table 2, which are particularly designed and used in wind turbines.

Table 2.

Airfoil Data Base

\begin{tabular}{|c|c|c|c|}
\hline $\begin{array}{c}\text { Airfoil } \\
\text { number }\end{array}$ & Airfoil standard & $\begin{array}{c}\text { Airfoil } \\
\text { number }\end{array}$ & Airfoil standard \\
\hline 1 & NACA $63-215$ & 23 & FX 61-163 \\
\hline 2 & NACA 63-218 & 24 & FX 61-168 \\
\hline 3 & NACA 63-221 & 25 & FX 61-184 \\
\hline 4 & NACA $63-415$ & 26 & FX 38-153 \\
\hline 5 & NACA $63-418$ & 27 & FX 66-S-161 \\
\hline 6 & NACA $63-421$ & 28 & FX 66-S-196 \\
\hline 7 & NACA 64-415 & 29 & FX 66-S-196 V1 \\
\hline 8 & NACA 64-421 & 30 & FX 66-17A-17 \\
\hline 9 & NACA $65-415$ & 31 & FX 66-17AII-182 \\
\hline 10 & NACA $65-421$ & 32 & NACA 4415 \\
\hline 11 & FX S 02/1-158 & 33 & NACA 4412 \\
\hline 12 & FX S 03-182 & 34 & S814 \\
\hline 13 & FX S 02-196 & 35 & S809 \\
\hline 14 & FX 60-126/1 & 36 & E387 \\
\hline 15 & FX 60-157 & 37 & SD2030 \\
\hline 16 & FX 60-177 & 38 & S822 \\
\hline 17 & FX 63-137 & 39 & S834 \\
\hline 18 & FX 63-143 & 40 & SG6043 \\
\hline 19 & FX 63-145 & 41 & SG6040 \\
\hline 20 & FX 63-147 & 42 & SG6041 \\
\hline 21 & FX 63-158 & 43 & SG6042 \\
\hline 22 & FX 61-147 & & \\
\hline
\end{tabular}

Three sections for blade are considered: root, mid and tip. Root of the blade is considered at $20 \%$ of the blade. Selected section for optimization is middle of the root. The second part of the blade is mid which is between root and tip; selected section in this part is middle of the blade ( $50 \%$ of blade radius).The third part is tip which is $5 \%$ of blade end. Figure 3 shows three parts of the blade.

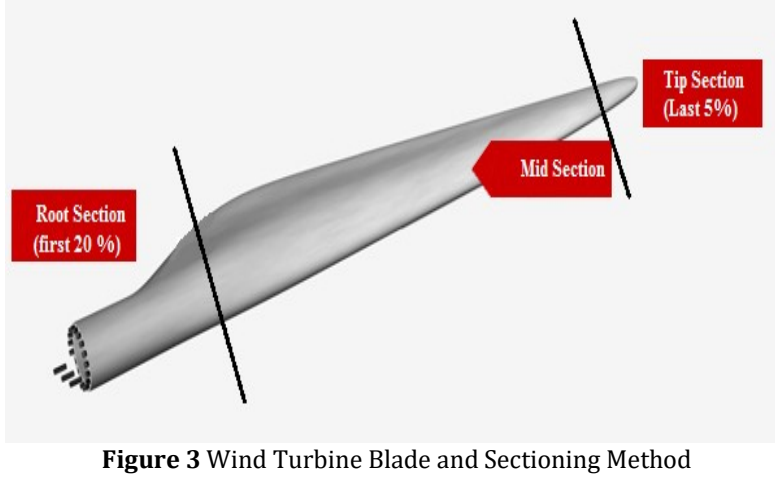

According to this method, the blade will have two intersections: (1) Intersection between root and mid, (2) Intersection between mid and tip. Airfoil type will affect blade thickness, which can be easily solve by manufacturing methods and will not be an important problem especially in wooden blades.

Figure 4 shows the flow chart of optimization process. In this process after primary assumptions determination, an airfoil and attack angle will be determined to be used for primary design. Using BEM code a primary design including all blade parameter such as chord distribution, relative wind angle distribution etc. would be determined. In the next step tree section will be selected as root, mid and tip. In each section, different variables will be substituted. Calculating output torque as the objective function will lead to optimum blade. It should be noted that section 1 , 2 and 3 are shown in figure 3 . Variables, which will be substituted in each section, are airfoil type, attack angle and chord.

Special features of the optimization process can be shortlisted in some steps. Firstly, a MATLAB code was written for calculations and was validated with experimental results. Secondly, a primary design was developed for each case study. This design is based on using just one airfoil across the blade. Then each case study blade was divided into three sections. The first section, root, which is $20 \%$ first part of the blade, the third section is tip which is $5 \%$ last of the blade and the rest of the blade is the second section which is mid. For each section, optimum variables (airfoil type, attack angle and chord) were selected to maximize output torque. One of the variables was airfoil type; a database of 43 airfoils was developed to be used in the 
optimization process. Finally the new optimized design leads to maximum output torque in each case study.

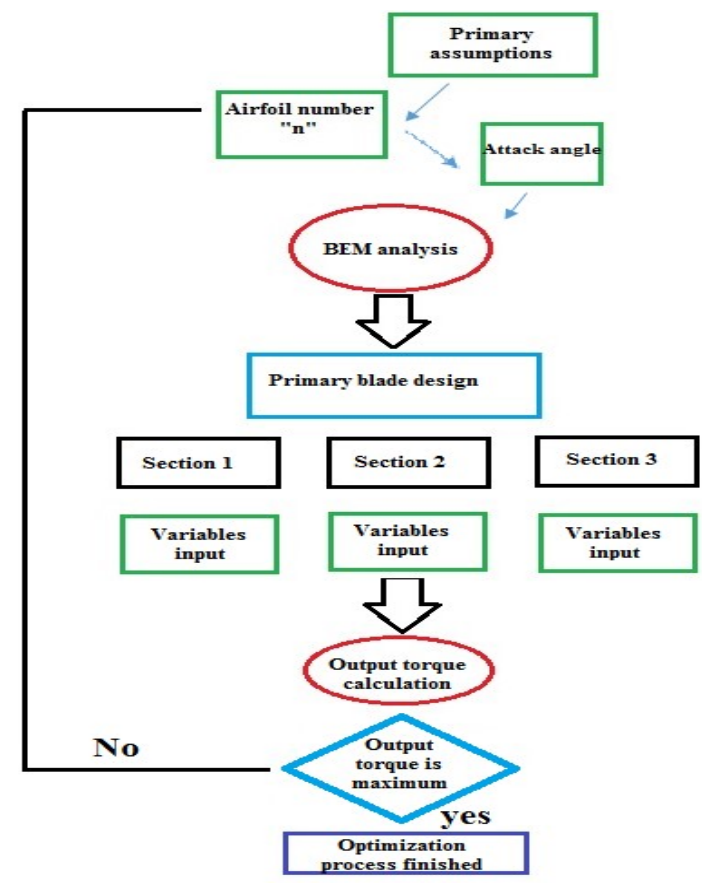

Figure 4 Optimization flow chart

\section{Results and Discussion}

All written codes must be validated by comparing the results with experimental data, analytical solutions or previously validated numerical solutions. In this research, actual experimental data of previously operated turbine were extracted which include primary condition of the turbine and output power. Primary conditions of the turbine were entered the code as initial assumptions and output results were compared with real values.

Turbine working condition was extracted according to table 3 to achieve this purpose.

Table3

Turbine working condition (Vestas wind system 1987]

\begin{tabular}{lc}
\hline Parameter & Value \\
\hline Number of blades & 3 \\
Turbine diameter & $20 \mathrm{~m}$ \\
Swept area & $314 \mathrm{~m}^{2}$ \\
Angular velocity & $45.8 \mathrm{rpm}$ \\
\hline
\end{tabular}

Results of MATLAB code were compared with experimental data for different wind speeds and are shown in figure 5 . According to equation 8, output torque of every element can be obtained. Summation of these elements will produce overall output torque of the blade. Blade output power, which is shown in Figure 5, can be obtained from Equation 10.

$$
P=T * \omega
$$

Where $\mathrm{P}$ is output power in $\mathrm{KW}, \mathrm{T}$ is output torque in N.m and $\omega$ is angular velocity in rad/s.

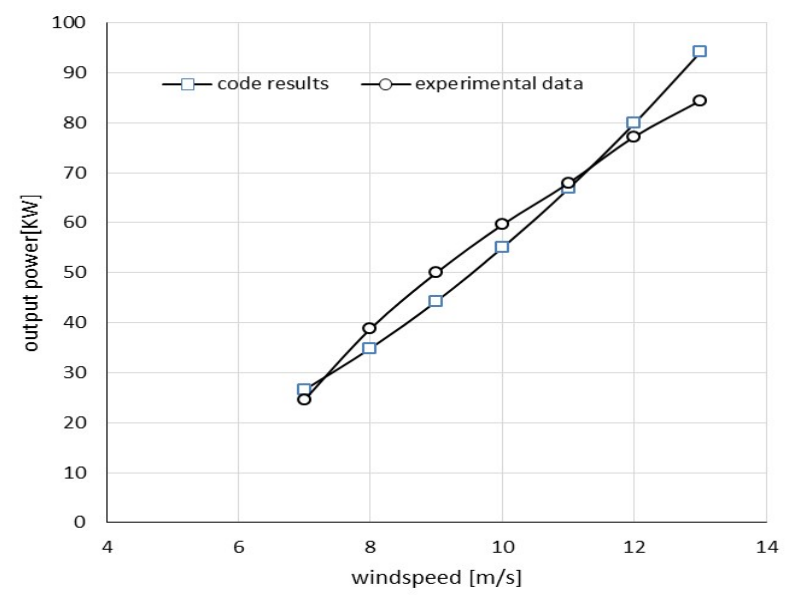

Figure 5 Comparison between calculated values of the code and experimental results

Figure 5 shows a very good agreement between calculated and experimental values. This means, this code leads to same design of previously operated blade and can predict the output power with less that $12 \%$ error. The main point of this validation is about $7 \%$ error in $7 \mathrm{~m} / \mathrm{s}$ wind velocity, which is completely acceptable error for a numerical code.

This code was not only used in primary design but also in optimization process and just inputs and outputs of two stages are different so this validation can be sufficient for all calculations.

Reynolds number will be very important due to its effect on lift and drag coefficients. Figure 6 shows variation of Reynolds number across $20 \mathrm{~m}$ blade. It is important to mention Reynolds number have the same variation in all considered blades, while the range of variation is different.

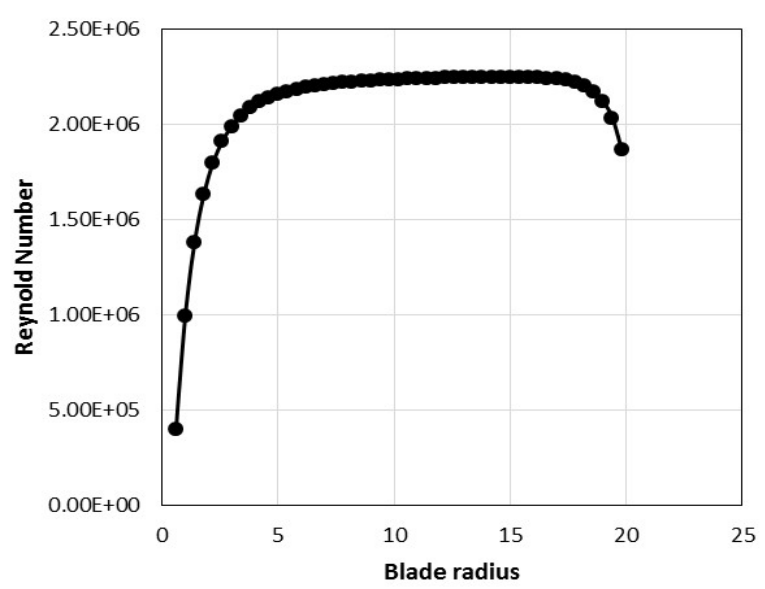

Figure 6 Reynolds number variation in 20 m blade 
Citation: Mohammadi, M., Mohammadi, A. and Farahat, S. (2016) A New Method for Horizontal Axis Wind Turbine (HAWT) Blade Optimization. Int. Journal of Renewable Energy Development, 5(1), 1-8. http://dx.doi.org/10.14710/ijred.5.1.1-8

$\mathrm{P}$ a g e $\mid 6$

Figure 6 obviously shows selected sections have three different Reynolds ranges (first $20 \%$ as root, $5 \%$ of last of the blade as tip and rest of the blade as mid) and the sectioning method of this paper exactly points different Reynolds ranges.

According to mentioned method, which is also shown in Figure 4, Optimization was performed on 7 case study blades. In each case study, this optimization will propose optimum values for airfoil type and attack angle for every blade section and an optimum chord distribution for the entire blade which leads to maximum output torque.

In small-scale blades, optimum airfoils and attack angles are the same; however optimum chord lengths are different.

As Table 4 illustrates, in all considered small-scale blades, for all three sections, "FX 66-S-196 v1" was selected, while attack angle was 8 degree, and according to Figure 7 different chord distribution are obtained in different blades. It should be mentioned that Table 4, Table 5 and Figure 7 shows the optimum variables ( airfoil type, attack angel and chord) which would lead to maximum output torque for selected case studies.

Table 4.

Results of $4.5 \mathrm{~m}, 6.5 \mathrm{~m}, 8 \mathrm{~m}$ and $9 \mathrm{~m}$ turbine blades optimization

\begin{tabular}{cccc}
\hline & $\begin{array}{c}\text { First } \\
\text { section }\end{array}$ & $\begin{array}{c}\text { Second } \\
\text { section }\end{array}$ & $\begin{array}{c}\text { Third } \\
\text { section }\end{array}$ \\
\hline Optimized airfoil & $\begin{array}{c}\text { FX 66-S- } \\
196 \mathrm{v1}\end{array}$ & $\begin{array}{c}\text { FX 66-S- } \\
196 \mathrm{v} 1\end{array}$ & $\begin{array}{c}\text { FX 66-S- } \\
196 \mathrm{v1}\end{array}$ \\
$\begin{array}{c}\text { Optimized attack } \\
\text { angle(degree) }\end{array}$ & 8 & 8 & 8 \\
\hline
\end{tabular}

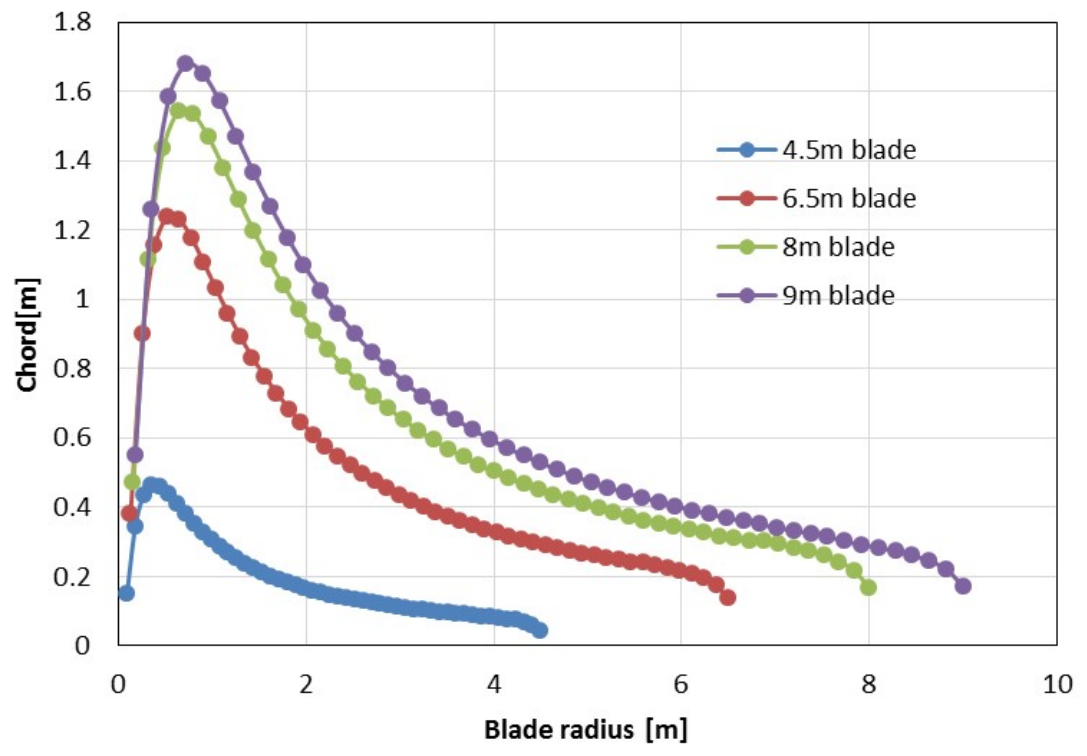

Figure 7 Optimized chord distributions in small-scale blades

Table 5 shows results of medium scale blades. As this table shows, despite small-scale blades, different airfoils with different attack angles have been selected.
Beside optimum airfoil type and attack angle, an optimum distribution of chord is obtained however due to large amount of data, optimum chord distribution of 15.5 blade is just shown as an example in Figure 8.

Table 5.

Results of 10 m, $15.5 \mathrm{~m}$ and $20 \mathrm{~m}$ turbine blades optimization

\begin{tabular}{|c|c|c|c|c|c|c|c|c|c|}
\hline \multirow{2}{*}{ Blade (m) } & \multicolumn{3}{|c|}{ First section (m) } & \multicolumn{3}{|c|}{ Second section(m) } & \multicolumn{3}{|c|}{ Third Section(m) } \\
\hline & 10 & 15.5 & 20 & 10 & 15.5 & 20 & 10 & 15.5 & 20 \\
\hline Optimized air foil & SG 6043 & $\begin{array}{c}\text { FX 66-S- } \\
161\end{array}$ & FX 63-137 & SG 6043 & $\begin{array}{c}\text { FX 66-S- } \\
196 \mathrm{v} 1\end{array}$ & SG 6041 & $\begin{array}{c}\text { FX 66-S- } \\
196\end{array}$ & $\begin{array}{c}\text { FX 66-S-196 } \\
\text { v1 }\end{array}$ & SG 6041 \\
\hline $\begin{array}{l}\text { Optimized attack } \\
\text { angle (degree) }\end{array}$ & 4.75 & 7 & 7.5 & 4.75 & 8 & 11.75 & 7 & 8 & 11.75 \\
\hline
\end{tabular}




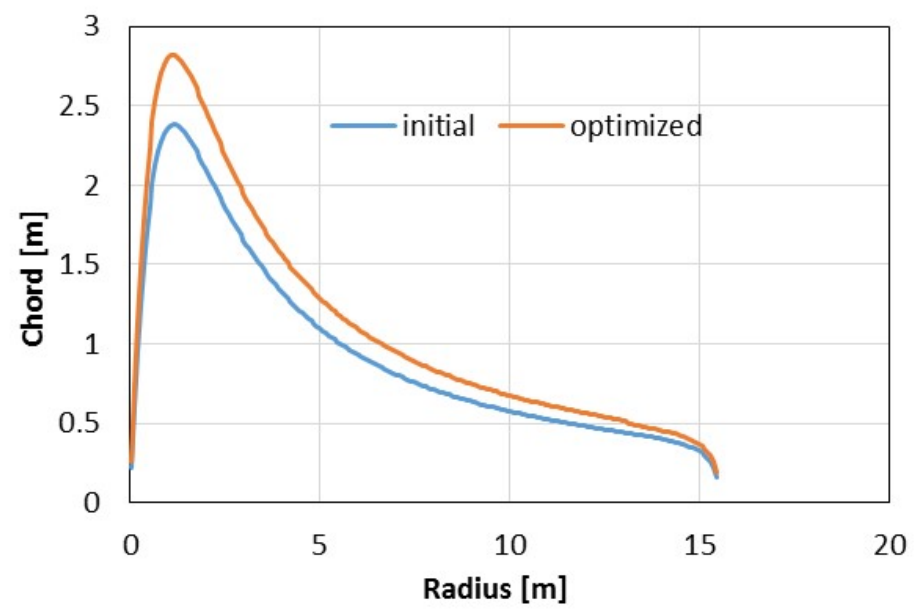

Figure 8 Comparison between chord distributions between initial and optimized chord lengths

The final important issue is the effect of proposed method on output torque. Results of this paper show in all case studies a dramatic rise in output torque happens which reaches to more than $25 \%$ increase in some case studies. Figure 9 shows an increase on output torque in every element across $15.5 \mathrm{~m}$ blade as an example of this increase. The initial blade is primary designed blade which used just one airfoil across the blade.

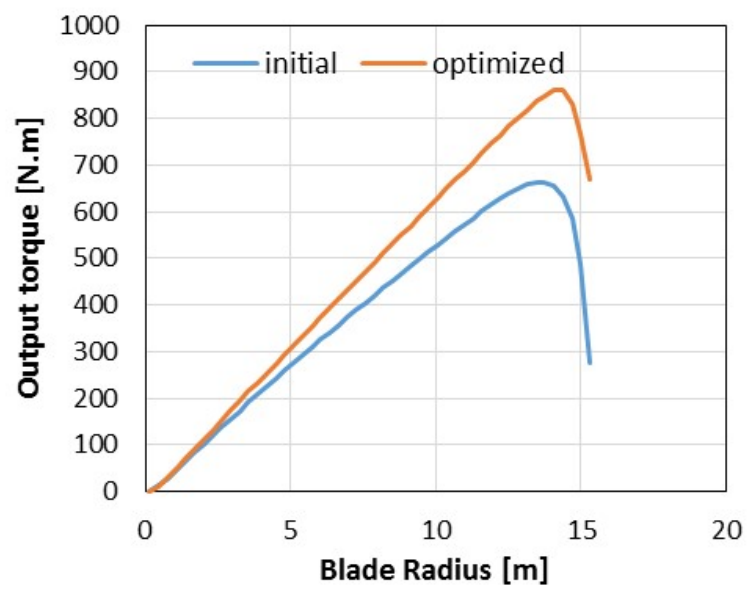

Figure 9 Comparison between outputs torques between initial and optimized blades

Figure 10 shows the amount of increase in optimization process rather than a simple design with NACA 63-215. In this figure the effect of using chord as variable is considered and it shows using three variables (airfoil type, attack angle and chord) in optimization process generally leads to higher increase than just using two variables (airfoil type and attack angle).
For each case study, the right column shows torque increase percentage with two variables optimization and the left column shows torque increase percentage with three variables optimization.

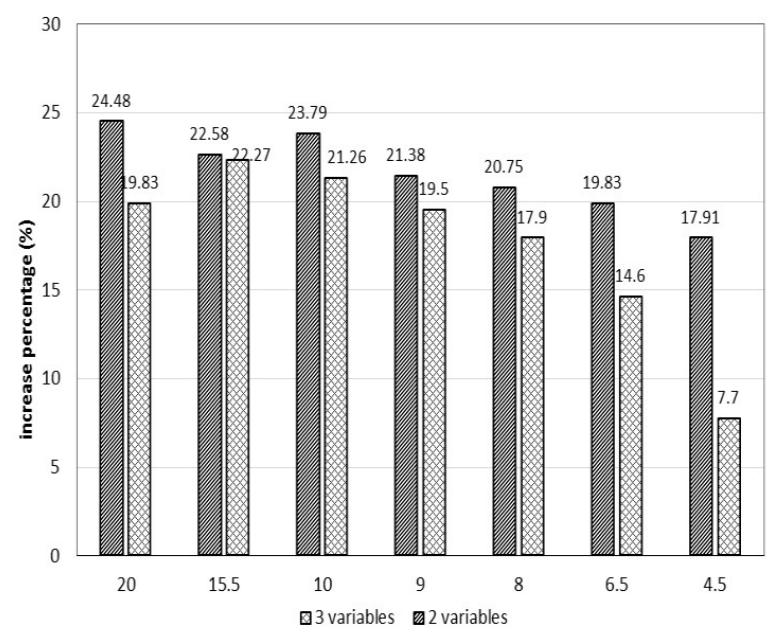

Figure 10 The amount of increase in each case study in optimization process in comparison to initial design

Figure 10 shows engaging chord in small-scale blades has a massive impact on the increasing output torque and in all case studies; using three variables could lead to a higher increase.

\section{Conclusion}

In this paper, seven small and medium scale wind turbines were optimized. Design and optimization were performed for conditions where average wind velocity is low $(7 \mathrm{~m} / \mathrm{s})$.

Three sections in root, mid and tip of the blade were considered. The reason of different section selection 
Citation: Mohammadi, M., Mohammadi, A. and Farahat, S. (2016) A New Method for Horizontal Axis Wind Turbine (HAWT) Blade Optimization. Int. Journal of Renewable Energy Development, 5(1), 1-8. http://dx.doi.org/10.14710/ijred.5.1.1-8

$\mathrm{P}$ a g e $\mid 8$

was different conditions in root, mid and tip of the blade such as Reynolds number. Considering airfoils designed for wind turbines, the best airfoils with the best attack angles were selected for each section.

This research showed in small scale blades, just one airfoil and attack angle was selected for all sections. Comparing blades of different turbines shows this result is deduced in all of them. Considering results of medium scale optimization of three wind turbine blades with exactly same method, where three different airfoils and attack angles were selected across the blade, indicates that in considered small-scale blades, blades are not long enough to have various condition across the blade. In other words primary condition such as Reynolds number do not cause different airfoil selection, while in medium scale blades selection factors are different enough to choose another airfoil and attack angle.

These results also show FX 66-S-196 v1 is a very suitable airfoil for small-scale blades for low speed condition for all root, mid and tip of the blade.

Results also showed the effect of chord engagement in optimization process, which showed a higher increase in output torque rather than a just using airfoil type and attack angle as variables. Results of this research shows using this method can deduce nearly $20 \%$ increase in all considered blades.

\section{Nomenclatures}

\begin{tabular}{|c|c|c|}
\hline Symbol & & Description \\
\hline $\mathrm{B}$ & & Number of blade \\
\hline $\mathrm{C}[\mathrm{m}]$ & & Chord length \\
\hline & $C_{l}$ & Lift Coefficient \\
\hline & $C_{c}$ & Drag Coefficient \\
\hline $\mathrm{d} F_{N}[\mathrm{~N}]$ & & $\begin{array}{l}\text { Component of total force } \\
\text { located parallel to axial force }\end{array}$ \\
\hline$d F_{T}$ & & Component of total force \\
\hline & & $\begin{array}{l}\text { located in the plane of blade } \\
\text { rotation }\end{array}$ \\
\hline$P[\mathrm{~W}]$ & & Output power \\
\hline $\mathrm{R}[\mathrm{m}]$ & & Blade radius \\
\hline $\mathrm{r}[\mathrm{m}]$ & & Sectional blade radius \\
\hline $\mathrm{U}[\mathrm{m} / \mathrm{s}]$ & & Relative wind velocity \\
\hline$U_{r e l}[\mathrm{~m} / \mathrm{s}]$ & & Relative wind velocity \\
\hline$\alpha\left({ }^{\circ}\right)$ & & Angle of attack \\
\hline$\phi\left(^{\circ}\right)$ & & Angle of relative wind \\
\hline$\rho\left(\mathrm{kg} / \mathrm{m}^{3}\right)$ & & Air density \\
\hline$\omega(\mathrm{rad} / \mathrm{s})$ & & $\begin{array}{l}\text { Angular velocity of stream } \\
\text { after the blade }\end{array}$ \\
\hline$\Omega(\mathrm{rad} / \mathrm{s})$ & & Blade angular velocity \\
\hline
\end{tabular}

\section{References}

Allalia, K., Azzaga, E., Labara,H. (2015) Techno-economic Analysis of a Wind-Diesel Hybrid Power System in the South Algeria. Int.Journal of Renewable Energy Development, 4(2) 137-142.

Cencelli, N. (2006). Aerodynamic Optimization OF a Small-Scale Wind Turbine Blade for Low Wind speed Conditions. Master of Science thesis report.

Chen, J., Wang, Q. , Shen, W., Pang, X., Li, S., Guo, X. (2013). Structural optimization study of composite wind turbine blade. Materials \& Design, 46, p.247-255.
Gandomkar, A. (2008) , Wind potential assessment in Iran, Geography an planning journal.(in Persian)

Kulunk, E. (2011). Aerodynamics of Wind Turbines, Fundamental and Advanced Topics in Wind Power, Dr Rupp Carriveau (Ed.).

Mahmoodi, E., Jafari, A., Keyhanib, A. (2015) Wind Turbine Rotor Simulation via CFD Based Actuator Disc Technique Compared to Detailed Measurement. Int.Journal of Renewable Energy Development. 4 (3) 205-210.

Manwell, J., McGowan, J. (2009). Theory Design and Application. John Wiley and Sons, Second Edition, ch 3, pp.103-134.

Mohammadi, M. R., Mohammadi, A., Mohammadi, M., Neisi Minaei, H. (2016) Optimization of Small Scale Wind Turbine Blades for Low Speed Conditions. Journal of Clean Energy Technologies (JOCET), 4, (3), 140-143.

Mohammadi,M., mohammadi, A., Mohammadi, M.R. (2014) Potential Issue of Jet Stream and Its Energy Generation Potential in Iran. 22nd Annual International Conference on Mechanical Engineering, Shahid Chamran University of Ahvaz. (In Persian)

Nedaei, M. (2012) Wind Resource Assessment in Abadan Airport in Iran. Int. Journal of Renewable Energy Development (IJRED), 1(3), 87-97.

Polat, O., Tuncer, I. (2013). Aerodynamic Shape Optimization of Wind Turbine Blades Using a Parallel Genetic Algorithm. 25th International Conference on Parallel Computational Fluid Dynamics.

Pourrajabian, A., Mirzaei, M., Ebrahimi, R., Wood, D. (2014). Effect of air density on the performance of a small wind turbine blade a case study in Iran. Journal of Wind Engineering and Industrial Aerodynamics, Volume 126. p. 1-10.

Qafleshia, M., Kryeziub,D., Alikoa,L. (2015) Potential of Wind Energy in Albania and Kosovo: Equity Payback and GHG Reduction of Wind Turbine Installation. Int. Journal of Renewable Energy Development, 4 (1), 11-19.

Renewable energy Organization of Iran website, http://www.suna.org.ir/fa/aboutorganization/ationoffice/winde nergyoffice/windatlasmap, as accurate of November 2015.

Sedaghat, A., Assad, M., Gaith, M. (2014). Aerodynamics performance of continuously variable speed horizontal axis wind turbine with optimal blades, Energy. $77,752-759$.

Sharifi,A., Nobari,M. (2013). Prediction of optimum section pitch angle distribution along wind turbine blades. Energy Conversion and Management, 67, 342-350.

Vestas wind system (1987) manual chapter 2, pp. 1 to 12

Ying, P., Chen, Y., Xu, Y. (2015) an aerodynamic analysis of a novel small wind turbine based on impulse turbine principles, Renewable Energy, 75. 37-43.

Zhu, W., Shen, W., Sørensen, J., (2014). Integrated airfoil and blade design method for large wind turbines. Renewable Energy, 70, 172-183. 